\title{
Patterns for Online Discussions
}

\author{
O’Sullivan, Jill \\ Farmingdale State College \\ School of Business \\ osullija@farmingdale.edu
}

\author{
Zevallos, Raul \\ SUNY College at Old Westbury \\ School of Education \\ zevallosr@oldwestbury.edu
}

\begin{abstract}
Nowadays, online education is very

popular. Almost every school has

developed at least a few online courses, in

order to be competitive in the education

market. The main interaction for online

courses is based on online discussions.

Numerous schools are developing and conducting hybrid courses focusing on a combination of online and traditional learning, with the emphasis on virtual constant correspondence. Other schools are using a Learning Management System with a component for online discussions, as part of the curriculum for a traditional classroom setting; this virtual academic presence mirrors businesses 24/7 accessibility. Conducting and evaluating online discussions may be a difficult task for novice teachers who lack experience in their conduction and evaluation. Patterns for Online Discussions have emerged as tools to conduct and evaluate online discussions and offers solutions to evaluate online discussions. This paper discusses an adaptation of the Alexandrian Pattern structure as the core for online discussions.
\end{abstract}

\section{Introduction}

This research effort is adapting the Alexandrian Pattern structure to enhance the classic context of most online discussions. The Patterns discussed provide solutions to create a new context. Practical reinforcement is used to create the new context. Using these Patterns, faculty members develop and gain useful ways to engage students. At the same time, students are motivated to participate actively and dynamically, while learning the theoretical and conceptual applications of the required knowledge. The teachinglearning engagement experience between faculty members and students goes beyond what is expected; the process provides feedback to reflect on new ways of teaching. In other words, the teachinglearning process becomes a symbiosis among faculty members and students, generating an improved context. The usage of a management system media providing asynchronous and/or synchronous ways of communication is required.

\section{History and concept of Patterns}

The original definition of Patterns was introduced by Christopher Alexander: "Each Pattern describes a problem which occurs over and over again in our environment, and then describes the core of the solution to that problem, in such a way you can use this solution a million times 
over, without ever doing it the same way twice. Each Pattern is a three-part rule, which expresses a relation between a certain context, a problem, and a solution." Using generic terms, a Pattern is an abstract solution to a specific problem in a determined context. As per Christopher Alexander, a Pattern has three basic parts, the context, the problem and the solution. Today, Patterns are widely used in multiple disciplines.

\section{Why use Patterns for online discussions}

The usage of Patterns in different disciplines has engaged us in developing Patterns for online discussions. This paper discusses four basic Patterns that solve common problems arising in online discussions. One of the Patterns addresses the problem of encouraging students to participate actively in online discussions (Commenting on comments). The next Pattern fosters mastery of the subject matter (Aiming at the target). As with any other activity, the retrospective process is highly desired to improve online discussions and related situations. The third Pattern allows teachers to receive feedback from students to improve ways of teaching (Fueling and fanning the flame). The final Pattern allows teachers to provide students with a fair grading system; rewards for participation have to be done in a fair context (Fair-and-square).

For most faculty members, teaching is much more than a career; it is a passion. Teaching requires being involved and committed to their students and subject matter. Patterns for Online Discussions is a tool developed to improve teaching skills to support faculty members' passion for teaching.

\begin{tabular}{|l|l|}
\hline \multicolumn{2}{|c|}{ Patterns for Online Discussions } \\
\hline \multicolumn{1}{|c|}{ Objective } & \multicolumn{1}{c|}{ Pattern } \\
\hline $\begin{array}{l}\text { You want to } \\
\text { encourage students } \\
\text { for active and } \\
\text { dynamic } \\
\text { participation }\end{array}$ & $\begin{array}{l}\text { Commenting on } \\
\text { Comments }\end{array}$ \\
\hline $\begin{array}{l}\text { You want to guide } \\
\text { students for } \\
\text { mastery of the } \\
\text { subject matter }\end{array}$ & Aiming at the Target \\
\hline $\begin{array}{l}\text { You want to } \\
\text { empower students' } \\
\text { suggestions and } \\
\text { improve your ways } \\
\text { of teaching }\end{array}$ & $\begin{array}{l}\text { Fueling and Fanning } \\
\text { the Flame }\end{array}$ \\
\hline $\begin{array}{l}\text { You want to use a } \\
\text { fair grade system }\end{array}$ & Fair-and-Square \\
\hline
\end{tabular}

Proposed Patterns for online discussions

\section{Pattern Name: Commenting on comments}

Context: Participation in online discussions is required. This participation is or probably shall be the main source of interaction among students and the faculty members. Participative student postings do not always show clear knowledge of the material taught.

Problem: Discussions may reflect no effort and no mastery of knowledge. In addition, every posting is isolated, and there is no interaction among postings; discussions seem to be lacking engagement. Postings are very static.

Forces: Most of the faculty members are involved in imparting knowledge based on theory and concepts of the material to be covered; they are expecting a high level of participation by students. Students are posting their comments and have the impression of isolation with no perceived 
stimulus to engage in participation. Administration and faculty expect that an online discussion will naturally be wellstructured in order to make a real assessment of whether the learning objectives have been achieved.

Solution: Design the learning modules and discussions based on the material being taught. Provide stimulating incentives in practical applications that reflect material comprehension. In interaction with students, use constructive comments in timely responses to students, prompting their interest and creating a desire to continue with their participation. Use reinforcements while responding to comments on postings; as examples of positive reinforcement, faculty members may tell their students "good job," after they link a theoretical concept to a real life application. The comments shall clarify or reinforce concepts and theories; comments have the ability to control the movement and flow of the discussion, making it very encouraging to be a part of a dynamic intellectual interaction. Keep in mind; you are the main animator and responsible for creating an enticing environment for participation of students learning during online discussions.

The student faculty interaction is critical for students' wellbeing and has proven influential in their overall educational experience. Faculty members may reinforce students' future participation by reducing the current workload based on positive previous activity; for example: eliminating the requirement for case studies. This makes students more enthused to participate because they are receiving a benefit of less workload in the module.

Resulting Context: Comments on postings will build enthusiasm, courage, and help students to develop a desire for challenges. Faculty members will be able to encourage student to participate and provide motivation to students to discuss different options in accomplishing tasks and reaching objectives. Online discussion posting shall become dynamic and frequent. There will be a closer correlation between the comment and the theoretical subject matter of the course, if students are encouraged to think their way through the theories and concepts in the discussions. It will allow to better measure learning comprehension for the teaching-learning process.

\section{Possible disadvantages include:}

Implementing this Pattern may take a lot of time because faculty members have to get familiar with the Pattern and its usage. The faculty members may expect their students to demonstrate deeper knowledge; if it does not occur, faculty members might feel frustration. The faculty members have to be encouraging and enthusiastic even when students are not responding favorably. If the conversation is not stimulated to increase participation or learning, students will not gain the advantage of the subject matter. Students may be sensitive to unfavorable comments; this disadvantage could instill a bad impression of online learning in the course. In addition, students may not be willing to participate or may disrupt the discussion. Be cautious to not get ahead of the material covered and/or not limit students to just repeating or rewriting concepts.

Known uses: In his theory of Behaviorism, Burrhus Frederic Skinner proposes reinforcement to encourage desired behavior. An example, a behaviorist approach would be a student receiving extra points after doing an outstanding work on an assignment and then continuing to perform in an outstanding fashion. Rewarding students for accurate, timely and insightful postings motivates future involvement for discussion commenting. 
Rewarding hard working students, with less workload, works very well.

In comparative studies using applied behavioral analysis, students show greater learning when they share ideas, praising the efforts and helping peers to master knowledge.

The work of Benjamin Bloom considers that a person should develop their three domains: Affective, Psychomotor and Cognitive. This Pattern refers to the affective and cognitive domains; when faculty members praise students these promotes the development of the affective and cognitive domains.

\section{Pattern Name: Aiming at the target \\ Context: Every learning module has} specific discussion content required, based on the covered material and conditions or situations of where to apply acquired knowledge. Posted mini lectures, assignments and homework required provide a synergistic opportunity for related information in the module. Suggested readings might contain material not covered but closely related to the learning material in the module.

Problem: Students learn at different paces. Some of them might capture and master the concept, easier and quicker than their peers. This situation may create divergent postings, sometimes ahead, or sometimes away, from the central topic or objective.

Forces: The online courses include posted mini lectures which illustrate the main concepts, as well as case studies that might be applicable. The system for discussion allows students to create unlimited new threads. Therefore, some students with clear understanding and mastery of the material have the tendency to introduce uncovered material through other entities, such as websites, company data, and/or industry trends relevant to the discussion.
Some other students, slow learners, are posting comments according to their comprehension, showing no understanding of the theoretical concepts.

Solution: Monitor the discussion to reduce divergent postings. If this happens, encourage students to focus on the main idea without discouraging participation. Limit the number of new threads created to 3 or 4. Provide distinct opportunities for students to demonstrate comprehension through additional avenues. Encourage mutual help or mentoring among students, using emails and/or social networks; students mastering the material shall guide and support classmates to reach objectives and prove their successful applications of the material. Encourage real life example that correlate with the lessons subject. The correlation between theoretical concepts and real life application invigorates the discussion when students bring in their own experiences to solidify understanding of material.

Quizzes and tests will assist faculty members in assessing comprehension; projects will enhance the exhibition of student understanding.

Resulting Context: Focusing on the most important part of the material covered shall reinforce the knowledge acquired by students. At the same time, students will improve the learning techniques. Based on instructors effort in assisting students to gear their posts directly to the main theme of discussion, students will develop a better way to learn. Students' better comprehension of the need to closely relate their responding post to the material will allow them to accomplish what is sequentially required, according to the objectives in the syllabus. Students working together and hearing from other students, as they relate closely to the subject discussion, will reinforce the learning process. Bringing in their life 
experiences that reflects correlation to the material affirms learning.

Sharing and discussing ideas and examples with their peers solidifies the understanding. Students' continued attempts to post on the comments will strengthen their need to be direct and concise about the material. These systematic postings will encourage students to continue having meaningful discussions, allowing some peers to see where their posts are adding to the overall understanding and improving participation and interest.

If the faculty members' efforts are not aligned with "Aiming at the Target", students will be all over the place with their postings and limited knowledge of the material will be acquired, resulting in negative comments and negative image about the course, the instructor and/or school.

Possible disadvantages include: Students who mastered the material might get discouraged or disappointed, if they have limitations on postings. Also, some students may not be willing to mentor their peers. Students who do not see peers participation and instructor participation may get discouraged. Students who consider the instructor as not having control or the ability to entice participation might lose interest in fully participating in the course. Faculty members may get exhausted because of the amount of time invested to fully implement this Pattern.

Known uses: In any meeting, the activity of the coordinator is very important to cover the agenda and its purposes, in orderly and timely fashion; at some point, it may be necessary to remind the purpose of the meeting and/or the agenda's topic. Also, in any debate, the function of the monitor is crucial for the success of the debate; in the same way, once on a while, it may be necessary to remind the purpose of the debate.

\section{Pattern Name: Fueling and fanning the flame \\ Context: Every learning module has} discussions that require student input and participation. Faculty expects each student posting to show clear understanding of the material taught. Students' postings may reveal that they do not understand the material or they need some inspiring guidance for better comprehension.

Problem: There is a need for better teaching practices.

Forces: Faculty members are committed to covering and imparting all the required material; most faculty members have the tendency to successful cover this material. Students who did not master the beginning chapters (learning modules), may not master the next chapters, which may deter mastering of all material taught.

Solution: Administer anonymous surveys, one in the middle of the course and one at the end of the semester. Use questions targeted to identify how the student could learn more. The survey might include questions on mini lectures, activities, examples used to impart the material, styles of teaching, ways of correcting ideas and other considerations within the teachinglearning process. Some examples of questions for the survey could be used; did the video on topic "A" strengthen your understanding of the concepts?, what other activity could be used if the video was not available?, did the recent natural disaster that occurred in "Place B" illustrate the principles learned?

Send students a brief summary of findings from the surveys, shortly after their completion and request timely feedback. Resulting Context: The survey will provide feedback to be used for the 
retrospective process for the course development. This will motivate faculty members towards a state of continuous teaching improvement. If a survey is conducted during the middle of the semester, the students may see the value of their feedback exhibited during the rest of the semester which will motivate their involvement and participation for the remaining class discussions. When students notice that their suggestions are considered, they will tend to participate much more. When students participate more actively due to modification or implementation of activities based on their input they are empowered. Then, it is possible to observe what activities engage students. Engagement will lead to more efficient ways of teaching and faculty members will have the satisfactions of the results obtained.

Possible disadvantages include: Students may not consider surveys as a tool to assess the teaching experience. If there is only one survey and if it is done at the end of the semester, students may not consider participating on the survey, at all. The faculty members, as human beings, may be discouraged if the survey indicates a lot to improve.

Known uses: Project managers at the end of every project write a Lessons Learned section to improve performance on the next project. Software development teams use project retrospectives to recognize members, encourage team work and to not repeat mistakes. Skinner proposes on his Behaviorist Theory of Learning reinforcements to encourage desired behavior. Self reflective faculty members may adjust their teaching methodology to improve the teaching-learning process; instructors may entice involvement of outside curriculum activities that will bring the parties together for mutual subject matter involvement. These types of faculty and student contact will enhance the course and give the students a feeling of alignment with campus life and a solid engagement with the teaching-learning process.

\section{Pattern Name: Fair-and-square}

Context: Posts need to be graded, based on reflections of student understanding and mastery of the course material; mastery may include the ability to apply the material developed, as well as critical thinking. As a generic rule, students with deeper understanding of the material shall earn better grades.

Problem: It is very common for students to compare grades and scores. Some students consider the received grades unfair especially if they compared them to other students' grades, even when their responses do not qualify as equal to what they are comparing them to. Students' reactions to scores may show disappointment, frustration and unhappiness.

Forces: Postings have to be graded in a timely fashion. Faculty members are using personal criteria to score and grade all postings. Students whose comments were using the same principle but different examples are expecting similar grades and/or scores. The administration would like to have a common rule to measure postings.

Solution: Use the related rubric. Keep in mind that a rubric is a scoring tool for subjective assessments; it is a set of criteria and standards linked to learning objectives used to assess a student's performance. An example of a rubric for spelling could be: unacceptable (1 point), if there are eight or more errors; acceptable (2 points), if there are 3 to 7 errors; target ( 3 points), if there are there are 0 to 2 errors. If there is no implemented rubric, build one. Detail what is going to be accomplished based on standards; standards are the skills and 
knowledge base expected of students for a particular subject area at a particular grade level. Determine and delimit properly each dimension, for each criteria weight. Clearly post the rubric so it is accessible to students.

Resulting Context: Faculty members, using rubrics or setting parameters, shall make clear what aspects of the students' discussions and submissions are being evaluated; how they are evaluated; what is expected; and the time frames for submission. Using rubrics, or parameters, help students to improve the quality of postings; ultimately, resulting in students considering faculty members as fair graders. Students understand the course expectations better. Students who have access to graded module assignments, shortly after the module is complete, have a better idea of how they are doing in the class and can address any inconsistencies to the instructor immediately. Claims about unfair grades are reduced drastically. If rubrics are not used students may be troubled by the inability to understand how they have been graded; they would not know the criteria or base for the grade, considering this unfair and not satisfied with the instructor, course or institution. Possible disadvantages include: Faculty may grade mechanically. Learning is a process and the need for improvement should be taken in consideration. Students may be focusing on rote learning just to accomplish the parameters of the rubric. Known uses: To obtain professional accreditations educational institutions have to fulfill multiple requirements. Among those requirements to fulfill there are standards to meet. In order to attain these requirements, educational institutions create rubrics properly aligned to standards. Using a systematic approach, based on rubrics, educational institutions obtain the data that proves the various standards are met.

\section{Conclusions}

Patterns are solutions to problems developed in a specific context, generating a new context. As per Alexander, "You can use this solution a million times over, without ever doing it the same way twice."

The usage of these Patterns for Online

Discussions have enabled faculty to develop alternative methods to deliver newly improved context where students are encouraged to participate in discussion of how to accomplish tasks and reach objectives. Another attribute for these Patterns includes, when students noticed that their suggestions were considered, they participate much more. Finally, the implementation of rubrics, or parameters, while using Patterns, helps students to improve the quality of postings.

Using Patterns, faculty members have experienced high participation in online discussions resulting in increased quality of postings. The sense of the work well done is a moral reward for faculty members; it have empowered and fueled discussions. Verifying recent knowledge acquired by students, through online discussions, allowed faculty members to adjust or modify teaching techniques, and the satisfaction produced by students' accomplishments.

At this time, the Patterns have not been developed as a Pattern Language for Online Discussions, but they are being introduced.

\section{Acknowledgements}

We would like to thank our shepherd, Professor Mary Lynn Manns, for her help in making this set of stand-alone Patterns. 
We would like to thank our professors, Fred Grossman and Joe Bergin of Pace University, for their feedback and assistance. Additionally, we want to acknowledge our classmates for their valuable input; thanks to China Pankey, Sergio Boniche, and Josua Purba.

\section{References}

[1] Mary Lynn Manns and Linda Rising, "Fearless Change: Patterns for Introducing New Ideas,” AddisonWesley, 2005.

[2] Joe Bergin, "Patterns for Agile Development Practice” euroPLoP 2005.

[3] Coplien, James O. "Software Patterns." SIGS Books, New York, New York, 1996.

[4] Coplien, James O. “A Pattern Language for Writers' Workshops.” PLoPD 4 Book, 1999.

[5] Coplien, James O. Neil B Harrison "Organizational Patterns of Agile Software Development.” Prentice-Hall, Inc. 2004.

[6] Bergin, Joseph, "Fourteen Pedagogical Patterns for Teaching Computer Science.” PACE University.

[7] Bergin, Joseph, “A Pattern Language for Course Development in Computer Science."

[8] Bergin, Joseph, "Several more Pedagogical Patterns.”

[9] Bergin, Joseph, "Fourteen Pedagogical Patterns."

[10] Eckstein, Jutta. Marquardt, Klaus. Manns, Mary Lynn. Wallingford, Eugene. "Patterns for Experiential Learning."

[11] Caeiro, Manuel. Llamas, Martín. Anido, Luis. "E-learning patterns: an approach to facilitate the design of elearning materials."

[12] Ellaway, Rachel, "Patterns in ELearning Standards and Specifications.”
[13] Kerth, Norman, "Project Retrospectives,” Dorset House Publishing, 2001. 